4. Радциг Е.Ю. Инфекция ЛОР-органов, вызванная b-гемолитическим стрептококком группы А, в амбулаторной практике //ConsiliumMedicum. Педиатрия (Прил.). 2016.№ 4. С. 55-58

5. Крюков А.И., Товмасян А.С., Жуховицкий В.Г. Биопленки в этиологии и патогенезе хронического тонзиллита // Вестник оториноларингологии. 2008. №3. С. 65-67.

6. Кузьмина Н.Н, Медынцева Л.Г, Белов Б.С. Ревматическая лихорадка: полувековой опыт изучения проблемы. Размышления ревматолога // Научно-практическая ревматология. 2017. № 55(2). С.125137.

7. Белов Б.С., Бабаева А.Р. Новые критерии диагностики острой ревматической лихорадки (предложения американской ассоциации сердца по пересмотру критериев Джонса) //Вестник Волгоградского государственного медицинского университета. 2016. С.3-7.

8. Пальчун В.Т. Классификация и лечебная тактика при хроническом тонзиллите // Вестник оториноларингологии. 2013. № 3. С. 8-11.

9. Пальчун В.Т., Гуров А.В., Аксенова А.В., Гусева О.А., Арзамазов С.Г., Набиева Т.Т.Современные подходы к диагностике заболеваний, сопряженных с хроническим тонзиллитом //Вестник оториноларингологии. 2013. № 3. С. 21-24.

10. Senska, G; Ellermann, S; Ernst, S; Lax, H; Dost, P. Recurrent Tonsillitis in Adults.Quality of Life After Tonsillectomy.Dtsch Arztebl Int 2010; 107(36): 622-8; DOI: 10.3238/arztebl.2010.0622.

11. Addressing the Challenges in Tonsillectomy Research to Inform Health Care PolicyA ReviewRishi Mandavia, BSc; Anne G. M. Schilder, PhD; Panagiotis A. Dimitriadis, MSc; et al. JAMA Otolaryngol Head Neck Surg. Published online July 6, 2017. doi:10.1001/jamaoto.2017.0964/.

12. AAO-HNS Guidelines for Tonsillectomy in Children and Adolescents. AMBERRANDELAmericanFamilyPhysician. 2011 Sep 1;84(5):566-573.

13. Крюков А.И., Аксенова А.В., Захарова А.Ф., Чумаков П.Л, Жук Л.Г.Особенности эпидемиологии хронического тонзиллита в современных условиях оказания специализированной ЛОР-помощи //Вестник оториноларингологии. 2013. № 3. С. 4-7.

\title{
Петров Ю.А. \\ Изменения в женских половых органах при внутриматочной контрацепции
}

Ростовский государственный медицинский университет МЗ РФ (Россия, Ростов-на-Дону)

doi:10.18411/spc-18-01-2018-10

idsp: 000001:spc-18-01-2018-10

\section{Аннотация}

Изучены частоты и особенностей пролиферативных процессов эндометрия, эндо- и эктоцервикса у женщин, применяющих внутриматочные контрацептивы(ВМК). Гистологическое исследование соскобов, а также цитологическое изучение мазков из шейки матки и нижней трети цервикального канала проведено у 638 женщин, носивших инертные ВМК от 3 мес до 12 лет. Контрольную группу составили пациентки (не пользующихся контрацепцией) в возрасте 20-46 лет, которым проведено кольпоцитологическое обследование, 96 из них выполнена штрих-биопсия эндометрия (перед, планируемым введением контрацептива).

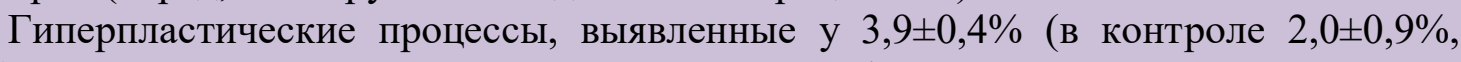
p $>0,05)$ в возрасте 23-42 лет, имели некоторые особенности, заключающиеся в том, что они в большинстве случаев носили характер смешанной формы, часто были транзиторны и хорошо поддавались терапии синтетическими прогестинами.

Ключевые слова: внутриматочная контрацепция, гиперпластический процесс, дисплазия эпителия, митотический режим, половой хроматин.

\section{Abstract}

Studied the frequency and characteristics of proliferative processes of endometrium, endo - and ectocervix in women who use the IUD. Histological examination of scrapings and cytological study of smears from the cervix and the lower third of the cervical canal was performed in 638 women bearing inert IUD from 3 months to 12 years. The control group consisted of patients (not using contraception), aged 20-46 years who underwent colpocytologic survey, 96 of them made the bar a biopsy of the endometrium (before the planned introduction of the contraceptive). 
Hyperplasia was diagnosed in $3,9 \pm 0,4 \%$ (in control $2,0 \pm 0,9 \%, p>0.05$ ) at the age of 23-42 years. Glandular hyperplasia of the mucous membrane of the uterus, is diagnosed when women use the IUD, had some features, namely that they in most cases had the character of a mixed form, were often transient and well resisted therapy with synthetic progestins.

Key words: intrauterine contraception, hyperplastic process, epithelial dysplasia, the mitotic mode, sex chromatin.

Среди современных методов предупреждения беременности в нашей стране одними из наиболее распространенных являются внутриматочные контрацептивы ВМК $[19,13,14,17,20]$. При изучении женских половых органов на фоне внутриматочной контрацепции выявлены различные состояния слизистой $[1,6,7,8,9,15]$. Однако до сих пор остается спорным вопрос о возможности возникновения предраковых процессов и рака слизистой оболочки тела и шейки матки при использовании ВМК $[3,7,22]$.

Цель работы: изучение частоты и особенностей пролиферативных процессов эндометрия, эндо- и эктоцервикса у женщин, применяющих ВМК.

Материал и методы: гистологическое исследование соскобов, а также цитологическое изучение мазков из шейки матки и нижней трети цервикального канала проведено у 638 женщин, носивших инертные ВМК от 3 мес до 12 лет. Контрольную группу составили 600 пациенток (не пользующихся контрацепцией) в возрасте 20-46 лет, которым проведено кольпоцитологическое обследование, 96 из них выполнена штрих-биопсия эндометрия (перед, планируемым введением контрацептива).

Гистологические срезы окрашивали гематоксилином и эозином, по Фельгену, цитологические препараты - азур-эозином. С целью комплексной оценки выявленных гиперпластических процессов эндометрия изучали содержание полового хроматина (ПХ) и особенности митотического режима (МР) клеток железистого эпителия и сравнивали с таковыми для -нормального эндометрия средней стадии пролиферации $[4,10,11,18,16]$. Определяли митотический индекс (МИ — число митотически делящихся клеток на 1000 клеток, об. 90, ок. 10), процентное соотношение фаз митоза, общее число патологических митозов и количество различных форм патологии кариокинеза, выраженное в процентах к общему числу митозов. Подсчет ПХ производили в срезах с реакцией Фельгена при увеличении до 1200 раз. Число эпителиальных клеток, содержащих ПХ, подсчитывали в 2-3 участках среза с выведением средних показателей в процентах[2].

С этой целью изучали не менее 300 клеток в каждом срезе. Полученные данные обрабатывали статистически с использованием критерия достоверности Фишера Стьюдента.

Результаты исследования свидетельствуют об отсутствии злокачественного роста в эндометрии женщин, применявших ВМК. Гиперпластические процессы выявлены у 25 пациенток $(3,9 \pm 0,4 \%$, в контроле $2,0 \pm 0,9 \%, \mathrm{p}>0,05)$ в возрасте $23-42$ лет. В $20 \%$ случаев имелись медицинские показания к удалению ВМК (в основном нарушение менструального цикла типа гиперполименореи), у остальных женщин ВМК извлечены по их желанию или из-за длительного ношения контрацептива. Частота железистых гиперплазий эндометрия не зависела от продолжительности внутриматочной контрацепции.

У 20 из 25 женщин для гиперпластических процессов было характерно разнообразие по строению желез эндометрия и их эпителиальной выстилки. Примерно в равном количестве в ней встречались пролиферирующие и секретирующие клетки. «Пролиферативно-маточный» эпителий (по классификации Л. И. Костиной) выстилал небольших размеров округлые железистые ходы. Просветы желез, выстланных «секреторно-маточным» эпителием, расширены больше, неправильной формы. Такая 
гистологическая картина оценивается исследователями как смешанная форма железистой гиперплазии [21,23].

В 5 наблюдениях была обнаружена пролиферативная форма железистой гиперплазии ( по Топчиевой)[23].

Митотический индекс при обнаруженных железистых гиперплазиях был примерно таким же, как и в контроле $(\mathrm{p}>0,05)$.Но возрастало количество метафаз $(\mathrm{p}<0,05)$ и патологических митозов $(\mathrm{p}<0,05)$. Спектр патологических митозов значительно не изменялся относительно контрольных данных. Среднее содержание ПХ' в железистом эпителии при обнаруженных гиперпластических процессах составило $26,5 \pm 1,4 \%$ (в контроле $33,9 \pm 2,1 \%, \mathrm{p}<0,05$ ).

10 женщинам было проведено цитогистологическое исследование эндометрия спустя 6-12 мес после извлечения ВМК. У 7 из них признаков гиперплазии не обнаружено. Еще 6 пациенткам в лечебных целях был назначен прием синтетических прогестиновпо контрацептивной схеме. При последующем цитогистологическом контроле через 3-4 мес и при дальнейшем наблюдении в течение года гиперпластических процессов эндометрия у них не выявлено.

Таким образом, железистые гиперплазии слизистой оболочки матки, диагностированные при применении женщинами ВМК, имели некоторые особенности, заключающиеся в том, что они в большинстве случаев носили характер смешанной формы, часто были транзиторны и хорошо поддавались терапии синтетическими прогестинами. Полученные нами данные совпадают с результатами других авторов [22,23]. Изменения МР и снижение уровня ПХ при диагностированных гиперпластических процессах были умеренно выражены, в то время как для предраковых изменений эндометрия характерны значительные нарушения МР и более резкое снижение уровня ПХ $[2,12]$.

В 15 наблюдениях $(2,35 \pm 0,2 \%$, в контроле $0,5 \pm 0,1 \%$; $<0,05)$ отмечены гиперпластические изменения эндоцервикального эпителия. Однако пролиферация была без признаков атипии, что в дальнейшем доказано гистологическим исследованием соскобов эндоцервикса. Частота гиперпластических процессов эндоцервикального эпителия возрастала в 2-3 раза при ношении ВМК в течение 7-12 лет $(6,0 \pm \pm 0,5 \%, \mathrm{p}<0,05)$. При динамическом цитологическом контроле после извлечения ВМК гиперпластические изменения шеечного эпителия в большинстве случаев не определялись.

У 12 пациенток $(1,88 \pm 0,2 \%$, в контроле $1,67 \pm 0,2 \%, \mathrm{p}>0,05)$ в цитограммах из шейки матки обнаружены дисплазии плоского эпителия, в 2 случаях они были умеренно выражены, в 10 - слабо выражены. Цитологический диагноз подтвержден гистологическим исследованием биоптатов. Повторное обследование этих пациенток проводилось каждые 3 мес. Прогрессирования процесса не выявлено ни в одном наблюдении. У 10 женщин внутриматочный контрацептив был удален, при последующем цитологическом обследовании в течение года после удаления ВМК в 6 случаях дисплазии подверглись регрессу, в 4 остались стабильными. Следовательно, у женщин с ВМК дисплазии эпителия шейки матки были, в основном, слабо выраженными и не носили упорного характера.

У 1 женщины $(0,15 \pm 0,01 \%$, в контроле $0,17 \pm 0,02 \%, \mathrm{p}>0,05) 33$ лет через 72 мес ношения ВМК был диагностирован внутриэпителиальный рак шейки матки.5пациенткам в лечебных целях был назначен прием синтетических прогестинов .

Выводы:выполненное исследование показало, что внутриматочная контрацепция не увеличивает частоты предраковых процессов и рака шейки матки и не приводит к возникновению рака эндометрия. Кроме того, установлены некоторые особенности пролиферативных процессов слизистой оболочки тела и шейки матки у женщин с ВМК. Выявление у части женщин гиперпластических изменений эндометрия 
и эндоцервикса, а также дисплазий эктоцервикса обосновывают необходимость регулярного клинико-цитологического обследования пациенток при внутриматочной контрацепции и после нее.

$$
* * *
$$

1. Боров В.Я, Майкопов Э.Ф.Тканевая реакция эндометрия женщин, длительно применяющих ВМК //Акушерство и гинекология. -1996. -№10. -С.5-9.

2. Боткина И.Е, Луцик Л.А. Влияние синтетическихпрогестинов на содержание полового хроматина в гиперплазированном эндометрии//Акушерство и гинекология. -1997. -№7. -С.33-35

3. Бохман Я.В, Сафронникова Н.Р. Онкологические аспекты гормональной и внутри ᄀматочной контрацепции. Л., 1991.

4. Ганина К.П. Цитогенетическая диагностика в онкоморфологии. -Киев:Здоровя, 1990.

5. Головин Д.И, Зусь Б.А. Половой хроматин в онкоморфологии // Архив патологии. -1991. -№12. C.3-7.

6. Грищенко В.И, Яковцова А.Ф, Лисс Н.Л. Морфологические изменения в эндометрии женщин при применении внутриматочного противозачаточного средства // Акушерство и гинекология. -1990. № 3. - C.41-42.

7. Деранкова Е.Б, Завгородняя В.И. К вопросу о длительности применения внутриматочной контрацепции //Вопросы охраны материнства и детства.-1996. -№2. -С.60-64.

8. Железнов Б.И, Ежова Л.С. Структурные и гистохимические особенности эндометрия женщин при применении внутриматочных контрацептивов различного типа //Акушерство и гинекология. 1999. -№7. -С.43-45.

9. Железнов Б.И, Орлова В.С, Хопина А.А. Структурные и морфофункциональные изменения эндометрия при внутриматочной контрацепции // Акушерство и гинекология. -1992. -№10. C. $26-30$.

10. Ежова Л.С,Железнов Б.И, Антипова Н.Б. Влияние внутриматочных контрацептивов на митотический режим эндометрия // Акушерство и гинекология. -1990. -№3. -C.39-40.

11. Казанцева И.А. Исследование митотического режима в морфологической диагностике опухолей //Архив патологии. -1990. №2. -С.77-82.

12. Крутьковская Н.П. Некоторые особенности пролиферации эндометрия при гиперпластических процессах // Архив патологии. -1999. -№10. -С.71-74.

13. Кузнецова И.В. Современная внутриматочная контрацепция //Гинекология. -2012. -№ 4. -С.6267.

14. МежевитиноваЕ.А. Внутриматочная контрацепция. -М.:МЕДпресс-информ,2001.

15. Петров Ю.А. Онкологический риск при использовании внутриматочных противозачаточных средств // Современные проблемы науки и образования. -2016. -№3. -С.131.

16. Петров ЮА. Состояние эндо- и эктоцервикса женщин, применяющих внутриматочную контрацепцию //Современные проблемы науки и образования. -2016. -№6. -С.7.

17. Петров Ю.А. Воздействие продолжительной внутриматочной контрацепции на эндометрий // Современные проблемы науки и образования. 2016. -№5. -С.6.

18. Петров ЮА. Изучение ДНК в слизистой оболочке матки при внутриматочной контрацепции // Международный журнал прикладных и фундаментальных исследований. -2016. -№4-5. -С.922925.

19. Петров Ю.А., Рымашевский Н.В, Ковалева Э.А. Внутриматочная контрацепция .Ростов-наДону:издательство Ростовского университета, 1990.

20. Петров Ю.А. Клинико-морфологическая характеристика и онкологические аспекты применения внутриматочных контрацептивов: автореф. дисс......канд.мед.наук. -Краснодар, 1984. -24c.

21. Савельева Г.М., Серов В.Н.Предрак эндометрия. -М.:Медицина, 1990.

22. Сафронникова Н.Р, Бохман Я.В.Онколлогические аспекты ановуляции. -Псков, 1990.

23. Топчиева О.М, Прянишников В.А, Жемкова 3.П. Биопсии эндометрия. -Л.:Медицина, 1998.

\section{Соколова А.Ю. \\ Мнемоника в медицинской практике}

Тверской государственный медиџинский университет

(Россия, Тверь)

doi:10.18411/spc-18-01-2018-11

idsp: 000001:spc-18-01-2018-11

Аннотация

Мнемоники - специальные приёмы запоминание информации. Мнемонические правила широко используются в Европе в медицинской практике и особенно в медицинском образовании. Они представляют собой слова, фразы, рифмы или образы, 